\title{
Methodology in a Pluralist Environment
}

\section{Sheila C Dow}

Published in Journal of Economic Methodology, 8(1): 33-40, 2001.

\begin{abstract}
The future role for methodology will be conditioned both by the way in which its content has developed in the direction of pluralism, and by the growth and specialisation of the field. The paper suggests that, for methodology to steer a successful course between foundationalism and relativism, there needs to be clarity about the meta-methodological frameworks which methodologists employ (since the pluralism applies to the fields of methodology and philosophy as well as economics per se). The case is made for regarding both the philosophy and methodology which ground practice as provisional, open to influence from practice itself.
\end{abstract}

$\underline{\text { Key words: }}$ pluralism, philosophy, communication

\author{
Department of Economics \\ University of Stirling \\ Stirling FK9 4LA. \\ +44-1786-467474 \\ s.c.dow@stir.ac.uk
}

September 2000 


\section{Introduction}

The field of methodology has gone through dramatic changes over the last few decades, not only in terms of content, but also in terms of the growth in the community of methodologists. Both developments raise the possibility that methodology's role has also changed.

The content of the field has changed in the direction of pluralism. Prior to the 1970s the small specialist methodological literature offered a limited, albeit sophisticated, range of methodological positions which in turn referred to a limited range of positions in the philosophy of science (such as some version of logical positivism or Popperianism). The general presumption was that it was feasible that agreement might be reached on the appraisal of methodology and philosophy of science, in the same way as agreement might be reached on the appraisal of economic theory. But now the content is more pluralist in a variety of senses (see Salanti and Screpanti, 1997). Not only is there a greater choice of both philosophies of science and methodology, but also there is no longer the same strength of expectation that agreement will be reached on how to appraise the various possibilities.

As if this doesn't make it difficult enough for practising economists seeking guidance from methodology, the field has become so large and specialised that much of the literature is inaccessible to outsiders. This growth raises particular sociological and rhetorical issues in terms of the relationship between economic methodology and economic practice. Indeed for some these sociological and rhetorical issues, as applied to economics itself, should replace conventional methodological discussion.

It is the purpose of this paper to consider the issues for methodology raised by this state of affairs. Specifically, we consider first the role for methodology in this pluralist environment. Then we focus on the communications issues raised by this role, and finally the relationship between methodology and both practice and philosophy are considered. The perspective adopted here is that of the practising economist $\mathrm{t}^{\mathrm{i}}$ : what does modern methodology have to offer?

\section{The Pluralist Environment}

As Hands (2000) argues, the 'new methodology' occupies a middle ground between foundationalism and relativism. Relativism had been a reaction to the foundationalist position that philosophy of science, and therefore methodologists, could feasibly establish guidelines for practice. During the 1980s and much of the 1990s, therefore, much of methodology veered in the direction of description rather than prescription. This phase was enormously productive in providing accounts of practice, an exercise which was not required by the foundationalist approach. But it was untenable to regard this as an exercise in pure description. Any account requires some kind of framework, or organising principles (such as Lakatos's Scientific Research Programs, or a focus on sociology, or on rhetoric, for example). Thus, although some of those who still aim to offer a non-prescriptive account of economics, as in the modern science studies approach, might demur from the term 'methodology', it is used here in a broad enough way to include all work which is concerned with the methods of 
conduct of economics. The pluralism we are concerned with therefore refers to the multiplicity of organising principles for such study.

The middle ground between foundationalism and relativism is populated by methodological analyses which, whether they purport to appraise or to describe, lay no claim to the capacity to reveal truth. This does not preclude the advocacy of particular frameworks; it is simply a recognition of fallibilism. But the act of choosing a framework involves (implicitly or explicitly) an appraisal of the range of possible approaches, and is thus to some extent prescriptive at a meta-methodological level. Thus even the explicitly non-prescriptive science studies approach embodies the judgement that this is the best way to organise a study of economic method. Implicit in most frameworks is also some form of prescriptive methodological stance: in a Lakatosian approach, for example, progress is identified on specific empirical grounds (understood in a particular way); McCloskey advocates a sprachethik as a guide to good rhetorical practice; critical realists advocate a particular view of what science can and cannot do; econometric methodologists advocate one approach or set of techniques over another. But, since there is no overarching framework on offer within which these analyses may be placed, how is the practising economist to navigate these waters?

Elsewhere (Dow, 1997) I have advocated a modified pluralism as a constructive methodology. The case was based on the argument that, while we have the best chance of building up a rounded picture of reality and its causal mechanisms by using a wide range of methods, a pure pluralist or eclectic methodology is unworkable. It would truly be a case of 'anything goes'. (The active tolerance of the postmodern approach, while attractive as such, does not help the economist to choose a way of going about practice.) The task then is for the economist to narrow down the range of methods, the questions to be addressed and so on; implicitly or explicitly this is done on the basis of world-view, or ontology (which could, for example, be a postmodern ontology of a fragmented reality). The resulting practice works most successfully not only if each economist operates within a community with a shared ontology, and a shared view of the range of methods to be used, questions to be asked etc, but also if there is sufficient awareness of alternative approaches to foster creative crossfertilisation, as opposed to conflict.

The same argument carries forward into the field of methodology itself. As methodologists, we have our own ontologies, our own views as to the questions to be asked, the means to address them, and so on. In making this argument, I am of course employing a meta-methodological framework for analysing methodology, as would any methodologist. I could provide a philosophical justification of this framework, but then there is the question of appraisal of alternative philosophical frameworks, none of which in turn can reasonably be regarded as laying claim to truth either.

It appears that the whole business is circular; there is no escaping the pluralism of methodologies or of philosophies. How should methodology proceed?

To assist in answering this question, let us pause to consider the possible purposes of methodology. I would suggest that the new methodology embodies variously some or all of the following four purposes: 
1. to inform debates in economics which have methodological origins

2. to reveal issues in economic practice as yet unaddressed

3. to guide progress in economics

4. to construct an analytical account of economic methodology.

In order to perform these functions, methodologists need to identify first the philosophical and methodological underpinnings of current practice. Where the underpinnings of the practice of protagonists in economics debate are different, the methodologist can clarify the nature of the debate by bringing these underpinnings to the surface. Where the methodologist can identify apparent incompatibilities between underpinnings and practice, the methodologist can make this clear to the economist, implying that underpinnings, practice, or both, require attention. All(!) this requires of the methodologist is the openness of mind to take on board a wide range of philosophical and methodological positions and to exercise the capacity to consider each body of economic practice on its own terms. For many this would be uncontroversial, although it is not at all straightforward to implement. The significance of context makes it hard for the methodologist to enter successfully into a range of different contexts. Indeed in practice it is hard to identify where the second role stops and the third begins.

It is the third role which is most clearly problematic in a pluralist environment, because different notions of progress can arise from methodological study and from practice. Foundationalist methodology saw its role primarily in this third category, and sought to establish agreement on criteria for progress. But in a pluralist methodological environment, the notion of progress itself is specific to each different approach (see Dow, 2000). As we saw, each approach has its own prescriptive program, unless it denies the third role altogether.

But even the fourth role, evident most notably in the science studies approach, is problematic. Just as discussion of historiography is focusing, among other things, on the significance of the framework of the commentator, so a methodologist reconstructing a methodological account of a particular theoretical development inevitably employs a framework.

The best we can hope to do, given the circularity of any justification, is to be explicit about the philosophical principles we bring to methodology and the methodological principles we bring to questions of practice. Just as it is a major role for the methodologist to tease out the philosophical and methodological underpinnings of economists, so it is incumbent on methodologists to be clear (within the community of methodologists as well as to practising economists) about their own underpinnings. Then practicing economists have some idea of what they are taking on board with a particular methodological framework. But this is easier said than done; it requires good communication, which involves sociological and rhetorical, as well as epistemological issues. ${ }^{\text {ii }}$ We turn to questions of communication in the next section.

\section{Communications Issues}

Communication is central to the success of the methodologist's role if it is defined at all in relation to practice. If we think of the methodological literature which has had 
most impact on the profession, it falls roughly into two categories. First, there is the hangover from the foundationalist era when methodology was treated hierarchically, drawing on philosophy of science and communicating guidance to economists. It is in this tradition that we find what used to be a standard element in the Introduction to introductory texts: an account of Popper's falsificationism, a drawing of the distinction between the normative and the positive, a contrasting of induction with deduction, and so on. Modern methodology tells us that these accounts usually misrepresented traditional methodology. First these ideas did not in fact emerge untainted by contextual considerations; it was a two-way process between philosophy of science and science. Second, the methodological literature fills out the full complexity of these various concepts and ideas which does not come across in introductory textbook treatments. But in addition it has been pointed out (notably by Blaug, 1980) that there is a wide divergence between this traditional approach to economics and practice.

While Blaug's book has had a sufficiently high profile that many practicing economists will be aware of his charge, there is no evidence of a change in practice towards conforming with traditional methodology. Aside from the natural unwillingness to take criticism on board, there was a further influence which encouraged economists simply to ignore methodology as traditionally understood. This strand of influence has come from practice itself - and in particular from influential practitioners. Thus a key publication was Friedman's (1953) case for instrumentalism, which was crucial in enhancing the significance of the predictive success of his monetarist model. He sparked off an argument about methodology whose importance stemmed from the debate over macroeconomic theory, but which at the same time questioned the relevance of much of the existing methodological literature concerned with theory construction. Another key publication was McCloskey's (1983) article on the significance of rhetoric. Coming to methodology as a respected cliometrician, McCloskey advocated the end of 'Methodology', meaning the older, prescriptive foundationalist methodology. But while McCloskey encouraged a fruitful new development within the new methodology literature (the study of rhetoric), the original article served to provide a further justification for practitioners to ignore methodology altogether.

Perhaps the most successful methodological work, in terms of impact, has been in the field of econometrics; practising econometricians tend to have a familiarity with the arguments of key figures, such as Sims, Leamer and Hendry, which is not common in relation to the rest of the methodological literature. This literature makes clear prescriptions in terms of econometric practice which can generally be understood, and taken on board by practitioners. As a form of methodological study clearly embedded in practice, this particular aspect of methodology has for many come to be understood as being coterminous with methodology as a whole. Further, since the tone in the econometric methodology literature is highly prescriptive, the impression is left that methodology is still foundationalist.

A fundamental problem for the rest of the methodological community therefore is how to get across the fact that the field, understood more broadly, has changed so radically, and is more concerned than in the past to understand practice and address issues arising from practice. The issue needs to be addressed that most economists probably identify methodology with McCloskey's 'Methodology', and feel more 
justified now in not giving it their attention There is the more complex question of getting across the content, as opposed to the nature, of the new methodology. In order to address this question we turn to consider the relationship between philosophy, methodology and practice. In the process we consider Smith's (1762-63) argument that the communication of ideas and their development are interdependent.

\section{Relationship between Philosophy, Methodology and Practice}

It is conventional to think of economic methodology in terms of a hierarchy: philosophy, methodology and practice. Indeed it has been a notable feature of some of the new methodology to open up the philosophical end of the hierarchy. A range of philosophical positions has been developed - different versions of realism, postmodernism, critical rationalism etc. It is then demonstrated that (whatever the starting point for the philosophy itself) taking any one of these positions as a startingpoint determines a particular approach to methodology, and in turn to practice. It is clear, then, that practising economists are implicitly making philosophical choices as well as methodological choices. If methodology is to perform any of the functions outlined above, then methodologists must be able to communicate with practitioners on the subject of philosophy as well as methodology.

If this were all, then the issue would be a purely pedagogic one, albeit an extremely challenging one. Clearly it is unreasonable to expect all economists to have the time, the skills or the inclination to understand the richness of the relevant methodological literature. It is up to methodologists to distil what is important and communicate it effectively. The same applies to philosophers. Since methodologists themselves implicitly or explicitly make philosophical choices, it is up to philosophers to put their arguments in such a way as to allow informed choice among those not trained in philosophy. In particular, if the case is being made for one philosophical approach over another, the gist of the arguments on different sides should be made generally accessible.

But the matter does not end here. In general, the notion of hierarchical authority is no longer generally accepted; neither philosophical arguments nor methodological arguments are taken on authority. In any case the whole notion of a hierarchy can be dangerously misleading, not only sociologically, but also epistemologically. Philosophy does not emerge from a vacuum, but from a context of which practice is a part. Therefore, while there is a logical hierarchy in that philosophy holds implications for methodology, and methodology for practice, practice in turn can hold implications for methodology and for philosophy. The recognition of this factor is important, not only for communications with practicing economists, but also for the content of methodology and philosophy. Thus, in particular, descriptive methodology, which is probably closest to practice, can play an important role in feeding material back into the development of methodology and philosophy. Smith (1762-63) suggested that there is less scope for the social sciences to go badly off-track than the physical sciences, because it was easier for the audience to relate the results of social science to their own experience. Further, he argued that the art of persuasion requires that attention be paid to the nature of the audience and to how to relate theory to what is already familiar to that audience; reason is employed where theory goes against common sense understanding, but there has to be some common ground (some basis 
for sympathy) as a starting-point for communication. Part of the process of theory development (in methodology as in economics) is to recognise when an inability to persuade is due to unsuccessful communication skills and when it is due to some inadequacy in the theory.

The emergence of the new methodology coincided with a move away from the methodologist (or philosopher) as authority. This was only one aspect of a more general move against authoritarianism, which encouraged economists not to feel bound by methodological strictures developed elsewhere. But economists do adhere to methodological strictures which are in general implicit. The fact that the new methodology takes seriously the methodology implicit in practice should, were it more generally known, endear methodologists more to practicing economists.

It was through considering how practice evolves that the current pluralism of methodologies, and philosophies, emerged. What is important now is that the resulting distinct approaches do not become invariant in the face of practice, so that the hierarchy of influence settles back into a uni-directional phenomenon, with the only influence running from philosophy to methodology to practice. Where some disparity appears between philosophy, methodology and practice, everything should be open for discussion; in a fallibilist, pluralist methodological environment, philosophical and methodological underpinnings can only be regarded as provisional and open to reasoned argument. The importance of the new methodology is that it offers a range of approached to practitioners and it is incumbent on methodologists to make their choice as informed as possible. But if methodology reverts to a state in which the options no longer connect with the concerns facing practitioners, the scope for influence will again be lost.

\section{Conclusion}

We have arrived at the point of emphasising the importance of economic practice in influencing methodology, a common theme in the new methodology. The emphasis has been put on the scope for economic practice to influence the practice of methodology as well as its content. In turn, it has been suggested that methodology can perform a range of functions designed to enlighten and inform economic practice. For the two-way influence to be successful there has to be effective communication between the levels of philosophy, methodology and practice, based on mutual understanding and Smithian sympathy.

There is no ultimate scope for escaping the circularity involved in employing frameworks for methodology, or philosophy. But the more informed philosophers, methodologists and economists are about the nature of the various frameworks and what they entail, the more effective will be the communication, the more readily will economists understand the full range of possibilities which the new methodology can offer, and the more practising economists will be able to exert their own influence on the field. 


\section{References}

Blaug, M (1980) The Methodology of Economics. Cambridge: Cambridge University Press.

Dow, S C (1997) Methodological Pluralism and Pluralism of Method, in Salanti and Screpanti (eds): 89-99.

Dow, S C (1999) Rationality and Rhetoric in Smith and Keynes, in R Rossini, G Sandri and R Scazzieri (eds), Incommensurability and Translation, Cheltenham: Elgar: 189200.

Dow, S C (2000) Prospects for the Progress of Heterodox Economics, Journal of the History of Economic Thought, 22(2):

Friedman, M (1953) The Methodology of Positive Economics, in Essays in Positive Economics, Chicago: Chicago University Press.

Hands, D W (2000) Economic Methodology is Dead: Long Live Economic Methodology: Thirteen Theses on the New Methodology', paper presented to the INEM Conference, Vancouver, June 2000.

McCloskey, D N (1983) The Rhetoric of Economics, Journal of Economic Literature, 21(June): 481-517.

Salanti, A and Screpanti, E (eds) (1997) Pluralism in Economics, Cheltenham: Elgar.

Smith, A (1762-63; 1983) Lectures on Rhetoric and Belles Lettres, ed. by J C Bryce, Oxford: Oxford University Press.

\footnotetext{
i In what follows, I will refer at times to 'methodologists' as distinct from 'practising economists' although there are of course many individuals who operate in both economics and economic methodology.

ii Adam Smith's work on rhetoric provides a rich source on the subject of combining rhetoric, sociology and epistemology when considering both the communication and development of philosophy and science; see Dow (1999).
} 